\title{
Verifying a Finite Element Analysis Methodology with Reinforced Concrete Beam Experiments
}

\author{
Naveen Revanna, Charles K. S. Moy, Theofanis Krevaikas \\ Department of Civil Engineering, Xi'an Jiaotong-Liverpool University, Suzhou, China \\ Email:n.revanna@xjtlu.edu.cn, cloo8000@uni.sydney.edu.au, theofanis.krevaikas@xjtlu.edu.cn
}

How to cite this paper: Revanna, N., Moy, C.K.S. and Krevaikas, T. (2020) Verifying a Finite Element Analysis Methodology with Reinforced Concrete Beam Experiments. Journal of Applied Mathematics and Physics, 8, 2549-2556.

https://doi.org/10.4236/jamp.2020.811190

Received: September 5, 2020

Accepted: November 23, 2020

Published: November 26, 2020

\begin{abstract}
This paper verifies the accuracy of a methodology recently proposed on reinforced concrete beam tested in flexure available from literature. This was implemented using the general purpose FEA software Abaqus. A very good agreement between numerical and experimental study was obtained. The compression failure, tension failure matched with experimental findings which shows the applicability of the methodology.
\end{abstract}

\section{Keywords}

Numerical, Abaqus, CDP

\section{Introduction}

Reinforced concrete beam is an important element in a structure as it carries and distributes the lateral loads coming on it. Manual design of reinforced concrete beams is a laborious task hence various FEA software were developed to fasten the design and analysis of reinforced concrete beams, among various available FEA software's Abaqus provides much convenience to the user as the properties of materials can be tailored to suit the analysis. Hence, Abaqus was chosen to analyse a reinforced concrete beam from literature [1]. The reinforced concrete beam was modelled and analysed in Abaqus FEA software. The results obtained i.e., load $\mathrm{v} / \mathrm{s}$ deflection was compared with the experimental results. A good comparison was obtained which will be explained further. The properties of concrete and steel are shown in Table 1 and Table 2 respectively.

\section{Test Specimen}

The test specimen consists of two $8 \mathrm{~mm}$ bars as tensile reinforcement, two numbers of $12 \mathrm{~mm}$ bars as compression reinforcement. Shear links were arranged closely in the shear spans at a spacing of $75 \mathrm{~mm} \mathrm{c} / \mathrm{c}$ whereas the constant 
Table 1. Concrete Properties [1].

\begin{tabular}{cccc}
\hline \multirow{2}{*}{ Concrete } & \multicolumn{3}{c}{ Concrete Properties } \\
\cline { 2 - 4 } & $\mathrm{fc}, \mathrm{MPa}$ & $\mathrm{ft}, \mathrm{MPa}$ & $\mathrm{Ec}, \mathrm{MPa}$ \\
\hline $\mathrm{C} 19.9$ & 19.9 & 2.1 & $22,904.69$ \\
\hline
\end{tabular}

fc, Concrete compressive strength; Ft, Concrete tensile strength; Ec, Elastic Modulus.

Table 2. Steel Properties [1].

\begin{tabular}{ccc|}
\hline \multirow{2}{*}{ Steel } & \multicolumn{2}{c|}{ Steel Properties } \\
\cline { 2 - 3 } & $\mathrm{fy}, \mathrm{MPa}$ & $\mathrm{fu}, \mathrm{MPa}$ \\
\hline $8 \mathrm{~mm}$ & 569 & 631 \\
$12 \mathrm{~mm}$ & 561 & 637 \\
\hline
\end{tabular}

fy, Yield stress; fu, Ultimate stress.

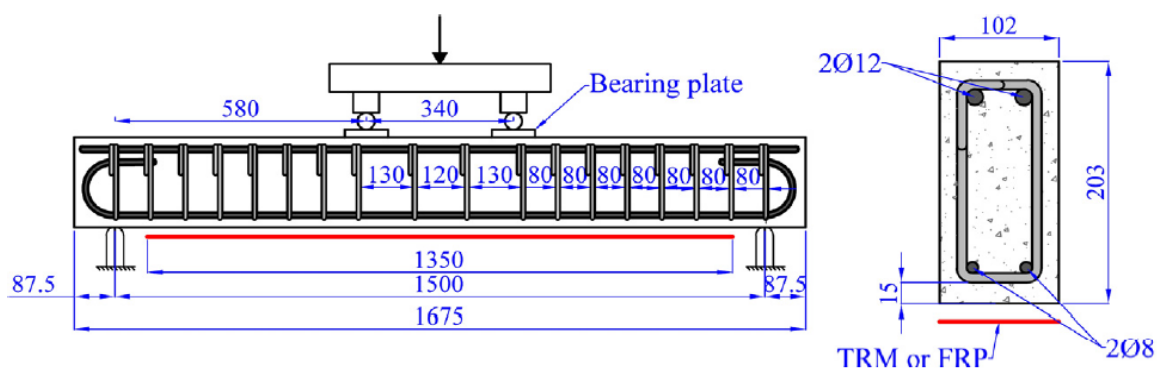

Figure 1. Details of reinforced concrete beam [1].

bending region was provided at $120 \mathrm{~mm} \mathrm{c/c}$ as shown in Figure 1.

\section{Numerical Model}

The numerical model consists of modelling all the components of the reinforced concrete beam as shown above. Concrete and loading steel plates were modelled using C3D8R, an 8-node linear hexahedral element, reinforcement including shear link was modelled as truss element, supports were modelled as roller with restraint in only y direction. Loading was applied as displacement controlled.

\section{Concrete Model}

Concrete was modelled using Concrete Damage Plasticity parameter (CDP). A standard model in compression and tension as provided by BAlfarah [2] was used to derive the CDP parameters of concrete in compression and tension. The compressive and tensile properties used are shown in Figure 1. A generalised compression and tension input curves can be seen in Figure 2. Steel reinforcement was modelled as elasto-plastic material according to Han model [3].

\section{Model Parameters and Calibration}

\subsection{Viscosity Parameter}

Various values from 0 to 0.0005 were tried to check the convergence of the nu- 
merical model. A value of zero always led to non-convergence, hence after running a check, it was identified 0.0005 would better suit to the needs of the numerical model and hence it was selected for the present simulation.

\subsection{Mesh Size}

Three mesh sizes were studied in order to study its influence on the numerical results. A mesh size of $15 \mathrm{~mm}$ was chosen as it showed good correlation with the experimental results. A plot showing the influence of different mesh size ranging from 15, 20, 25, 30 is shown in Figure 3.

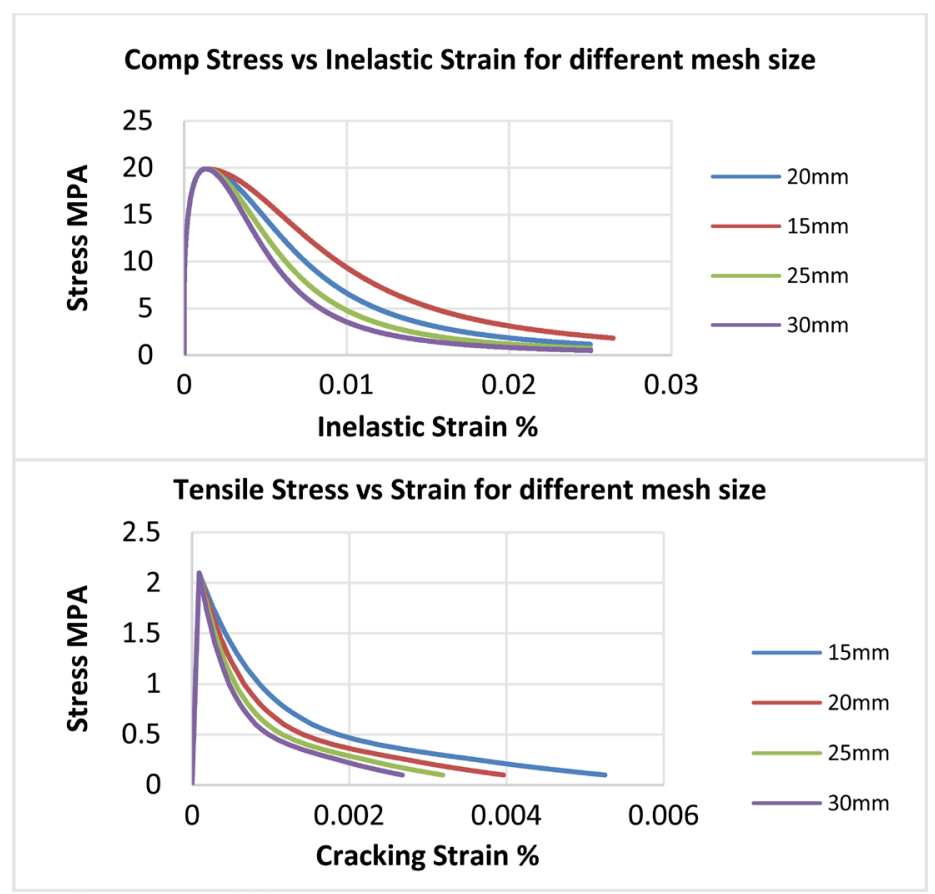

Figure 2. Input properties of concrete.

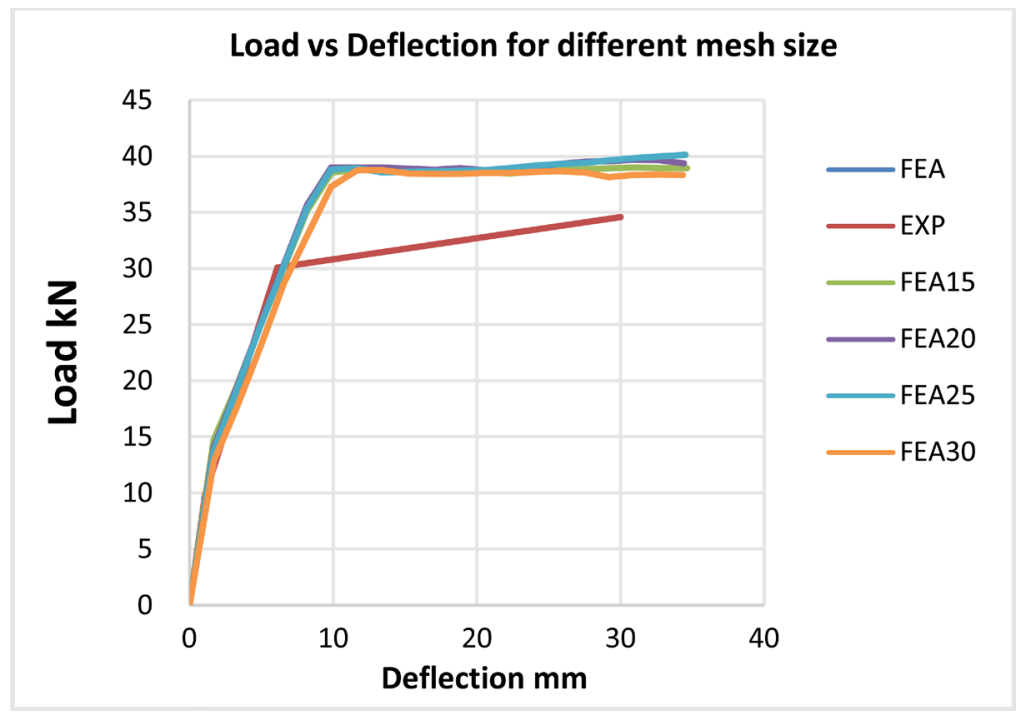

Figure 3. Mesh size study [1]. 


\subsection{Dilation Angle}

Dilation angle is a parameter which can influence the CDP parameters. Lesser values make the concrete material brittle whereas higher values make the concrete stiffer [4]. A plot of different values of dilation angles $(35,40,50,55)$ versus experimental result is presented in Figure 4. A value of dilation angle 50 was selected as it helped the model to converge and at the same time crack pattern matched with the experimental result.

\section{Analytical Results and Discussion}

From the previous parameters chosen the numerical model was run to ascertain its ability to predict experimental findings using the parameters shown in Table 3. The numerical results obtained showed a better agreement in terms of cracking load and yield load as noted from Table 4, however the ultimate load predicted was on higher side. The load vs. displacement curve plotted in Figure 6 and Figure 7 clearly explains the above findings.

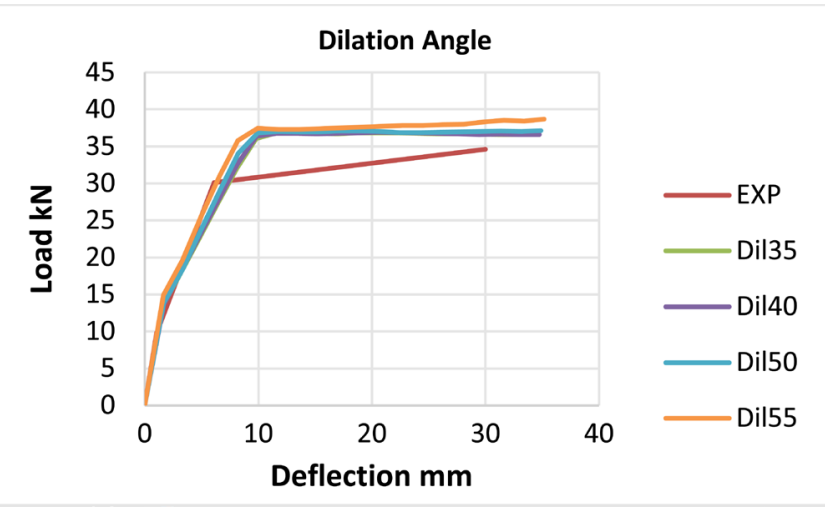

Figure 4. Dilation angle study [1].

Table 3. CDP parameters adopted

\begin{tabular}{cccccc}
\hline \multicolumn{2}{c}{ Concrete Damage Plasticity Parameters } & & $\boldsymbol{K}$ & $\boldsymbol{\mu}$ \\
\hline$\psi$ & $\lambda$ & fbo/fco & & \\
\hline 50 & 2.1 & $22,904.69$ & 0.667 & 0.0005
\end{tabular}
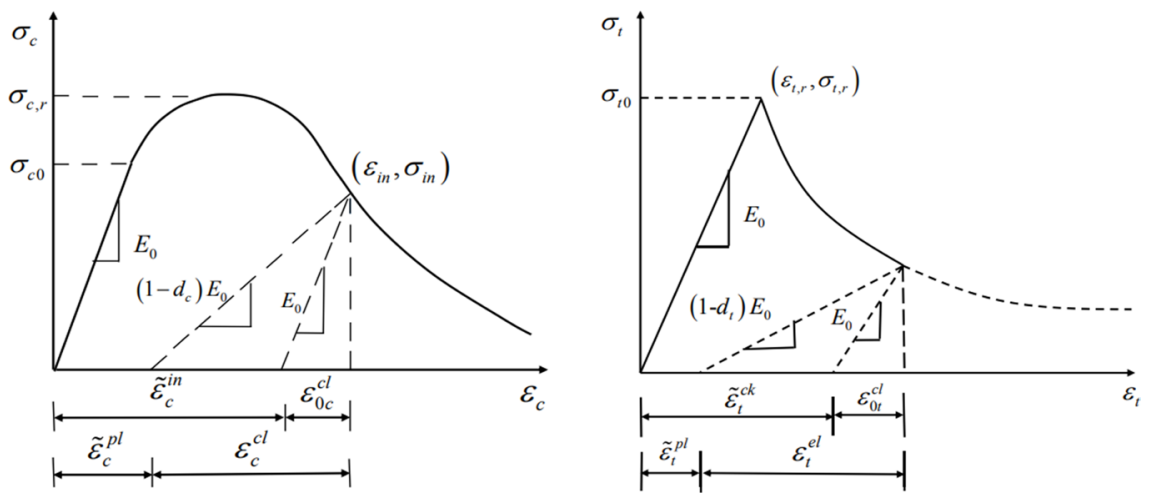

Figure 5. Typical compression and tensile stress strain curves [5]. 
The CDP model requires damage parameters to be input as compressive and tensile damages. These damage parameters were obtained as per the model and a damage value of 0 implies no crushing or tensile rupture whereas a damage value of 1 indicates total crushing of concrete in concrete and rupture in tension respectively. Figure 5 above shows a typical compressive stress vs strain, tensile stress vs strain plots and corresponding damage initiation points. The numerical result damage result in tension and compression matches well with the experimental findings. The concrete compressive zone damage was well predicted by the numerical model as seen in Figure 8. The tensile damage can be seen extending from left support to right support with majority of cracks located in the tensile zone. The tensile damage figure shows the extent of damage in the experiment. A damage value of $90 \%$ was selected as increased damage levels resulted in nonconvergence.

As it can be seen from Figure 6 and Figure 7 the results from numerical model are on the higher side compared to experimental findings by $50 \%$, $16.77 \%, 12.48 \%$ error in first crack load, yield load, ultimate load respectively and 56\%,34\%, 15.4\% error in corresponding deflection values in first crack load, yield load, ultimate load respectively. The higher first crack load predicted by the FEM model could to because more tensile stiffening.

Figures 8-10 shows various damage patterns as obtained from the FEA model. The extensive tensile damage seen in the FEA model agrees well with the experiment. The compression failure observed in Figure 8 shows the accuracy of the current model. Compression failure was mostly concentrated within the steel

Table 4. Experimental ${ }^{\star}[1]$ and Numerical results.

\begin{tabular}{ccccccc}
\hline & \multicolumn{3}{c}{ Load } & \multicolumn{3}{c}{ Displacement } \\
\cline { 2 - 7 } & $\begin{array}{c}\text { First Crack } \\
\text { Load (kN) }\end{array}$ & $\begin{array}{c}\text { Yield } \\
\text { Load (kN) }\end{array}$ & $\begin{array}{c}\text { Ultimate } \\
\text { Load (kN) }\end{array}$ & $\begin{array}{c}\text { First } \\
\text { Crack (mm) }\end{array}$ & $\begin{array}{c}\text { Yield } \\
(\mathrm{mm})\end{array}$ & $\begin{array}{c}\text { Ultimate } \\
(\mathrm{mm})\end{array}$ \\
\hline Experiment & 9.8 & 30.1 & 34.6 & 1.06 & 6.1 & 30 \\
FEA & 14.70 & 35.15 & 38.92 & 1.66 & 8.20 & 34.63 \\
\hline
\end{tabular}

*[1].

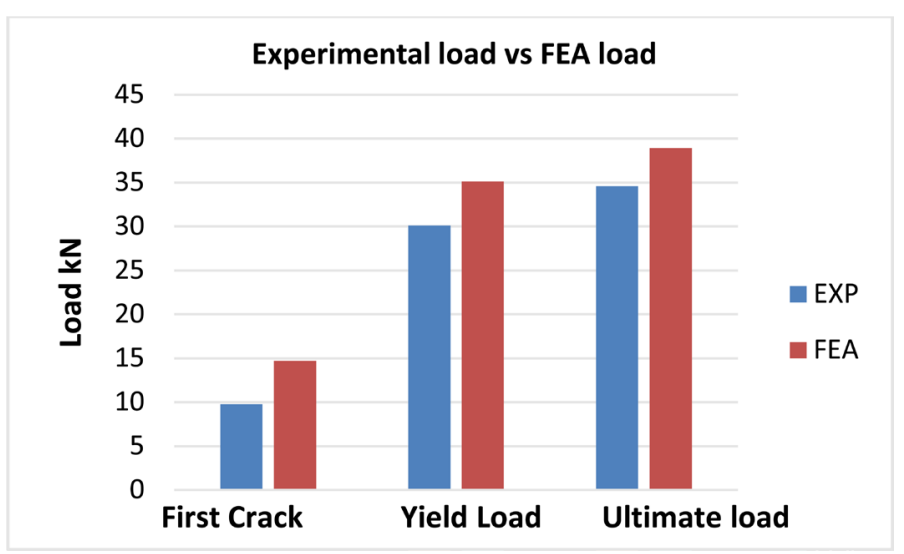

Figure 6. Experimental vs FEA load comparison. 


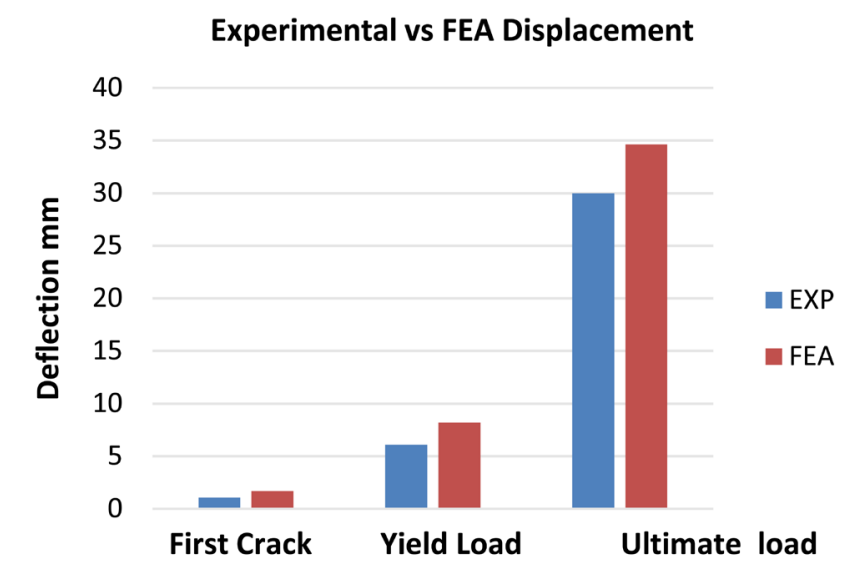

Figure 7. Experimental vs FEA load comparison.
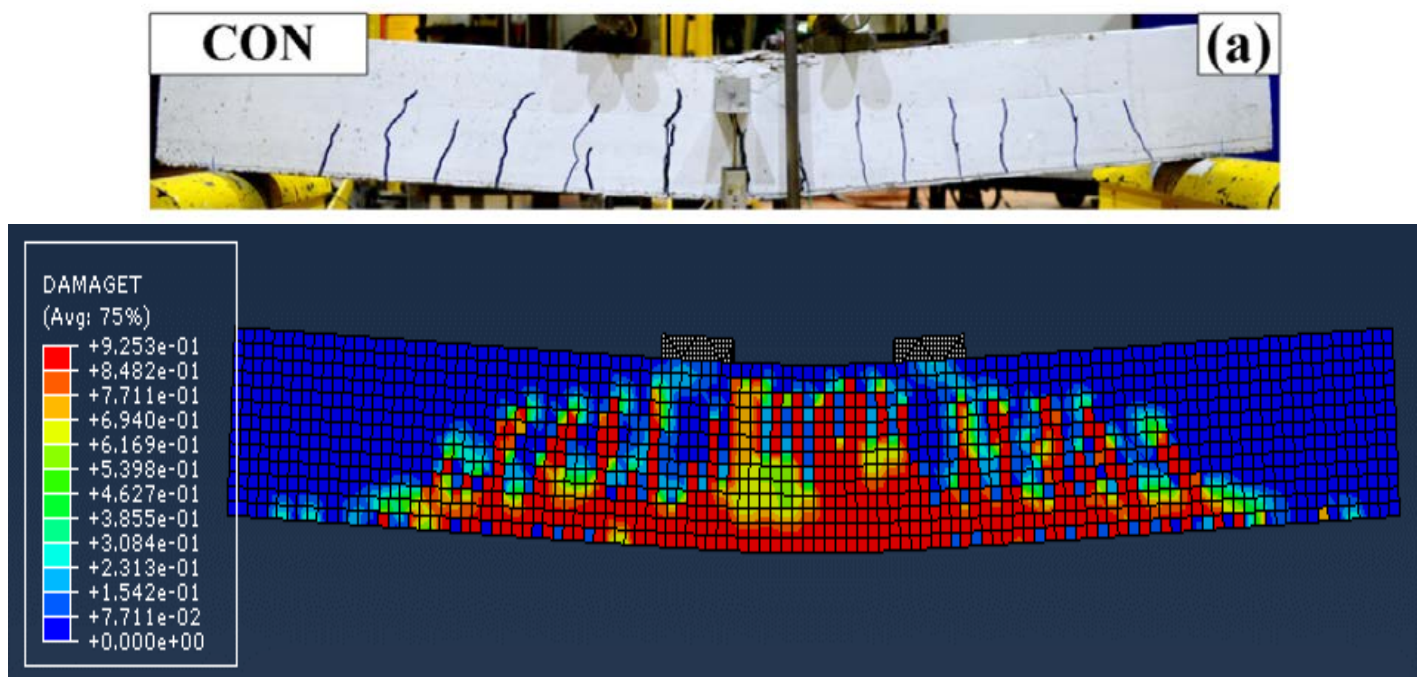

Figure 8. Tensile damage from FEA model and experiment [1].
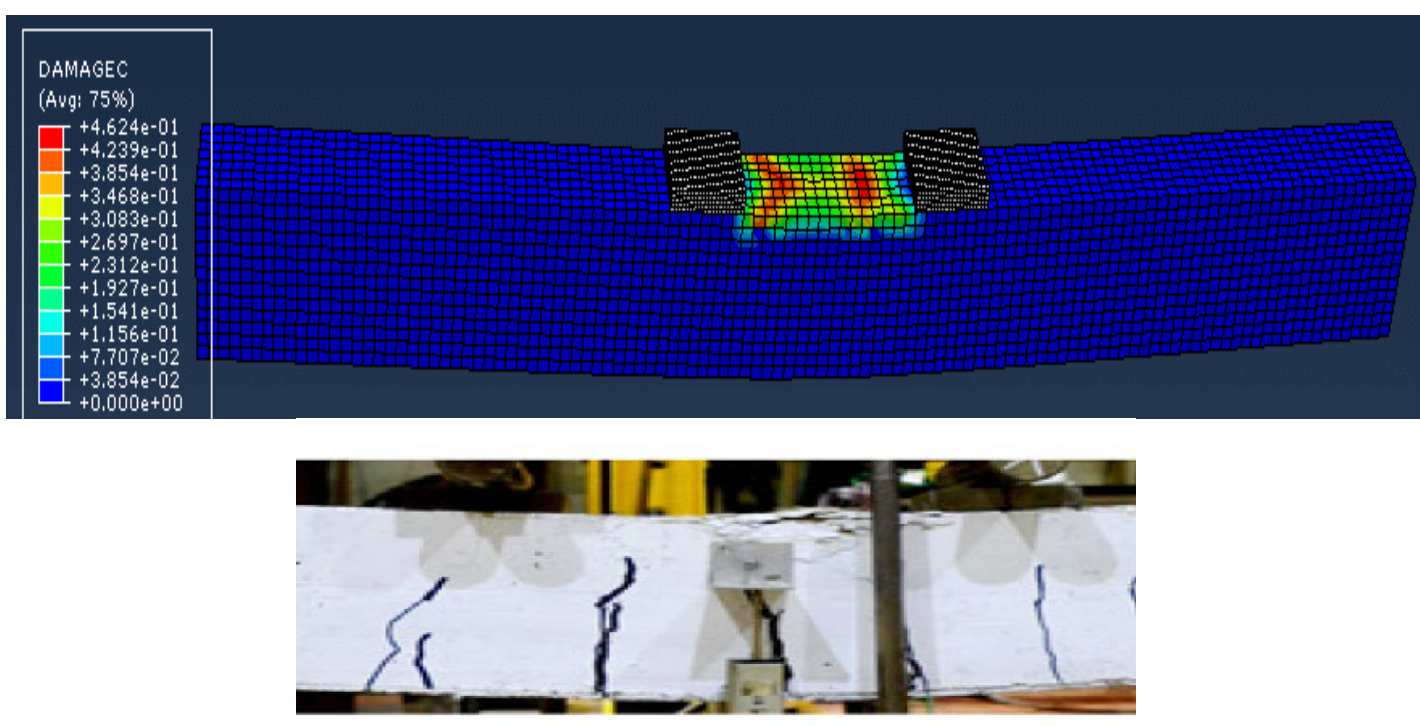

Figure 9. Compression damage from FEA model [1]. 


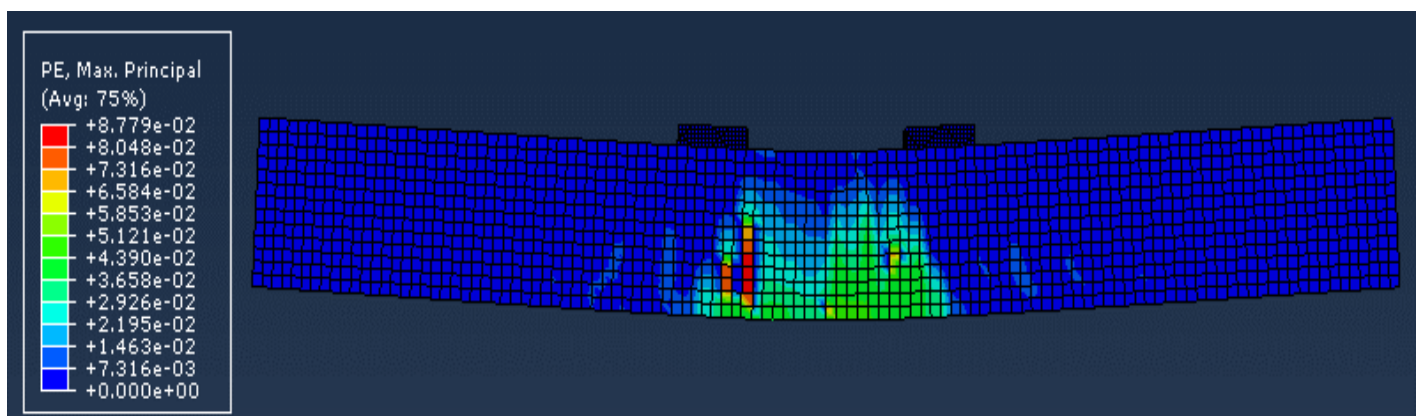

Figure 10. Plastic strain form FEA model.

loading plate span. The plastic strain is also used to trace cracking in reinforced concrete members, from the observed trend in PE, max most of the critical cracks are located with the pure moment region which again agrees well with the experiment.

\section{Conclusions}

From the study undertaken in this paper, the following conclusions can be drawn:

1) The FEA model adequately predicts the overall behaviour of the reinforced concrete beam, hence it can be further developed to model other types of reinforced concrete specimens.

2) Although the results from FEA model are on higher side compared to experimental findings, the yield load, ultimate load, yield displacement and ultimate displacement are very well close to the experimental findings which show that the current model could be accepted.

3) The FEA simulation perfectly predicts the compression crushing failure observed in the experiment.

4) The tensile damage obtained from the FEA study is also in line with the experimental findings.

5) From the above points it can be inferred that the developed FEA model could possibly be improved to further predict the accurate values of first crack, yield and ultimate loads.

\section{Acknowledgements}

The authors would like to acknowledge RDF 16-01-17 financial support from XJTLU.

\section{Conflicts of Interest}

The authors declare no conflicts of interest regarding the publication of this paper.

\section{References}

[1] Raoof, S.M., Koutas, L.N. and Bournas, D.A. (2017) Textile-Reinforced Mortar 
(TRM) Versus Fibre-Reinforced Polymers (FRP) in Flexural Strengthening of RC Beams. Construction and Building Materials, 151, 279-291.

https://doi.org/10.1016/j.conbuildmat.2017.05.023

[2] Alfarah, B., López-Almansa, F. and Oller, S. (2017) New Methodology for Calculating Damage Variables Evolution in Plastic Damage Model for RC Structures. Engineering Structures, 132, 70-86. https://doi.org/10.1016/j.engstruct.2016.11.022

[3] Han, L.-H., Yao, G.-H. and Tao, Z. (2007) Performance of Concrete-Filled Thin-Walled Steel Tubes under Pure Torsion. Thin-Walled Structures, 45, 24-36. https://doi.org/10.1016/j.tws.2007.01.008

[4] Behnam, H., Kuang, J.S. and Samali, B. (2018) Parametric Finite Element Analysis of RC Wide Beam-Column Connections. Computers \& Structures, 205, 28-44. https://doi.org/10.1016/j.compstruc.2018.04.004

[5] (2014) ABAQUSABAQUS Standard User's Manual, Dassault Systèmes Corp, Providence, RI (USA), Version 6.13. 